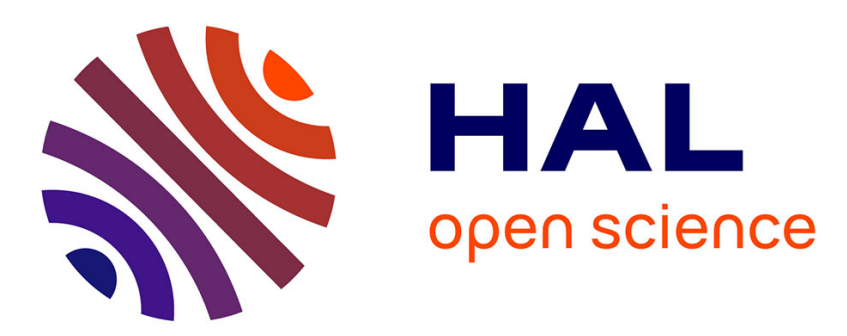

\title{
The Water Sensitivity of Iron Gall Ink and its Risk Assessment
}

\author{
Véronique Rouchon, Blandine Durocher, Eleonora Pellizzi, Julie \\ Stordiau-Pallot
}

\section{- To cite this version:}

Véronique Rouchon, Blandine Durocher, Eleonora Pellizzi, Julie Stordiau-Pallot. The Water Sensitivity of Iron Gall Ink and its Risk Assessment. Studies in Conservation, 2009, 54, pp.236 - 254. 10.1179/sic.2009.54.4.236 . hal-01435091

\section{HAL Id: hal-01435091 https://hal.science/hal-01435091}

Submitted on 13 Jan 2017

HAL is a multi-disciplinary open access archive for the deposit and dissemination of scientific research documents, whether they are published or not. The documents may come from teaching and research institutions in France or abroad, or from public or private research centers.
L'archive ouverte pluridisciplinaire HAL, est destinée au dépôt et à la diffusion de documents scientifiques de niveau recherche, publiés ou non, émanant des établissements d'enseignement et de recherche français ou étrangers, des laboratoires publics ou privés. 


\title{
The Water Sensitivity of Iron Gall Ink and its Risk Assessment
}

\author{
Véronique Rouchon, Blandine Durocher, Eleonora Pellizzi and Julie Stordiau-Pallot
}

Most Western manuscripts prior to the nineteenth century are written with iron gall inks. These are rich in iron, which enhances paper degradation. Many aqueous treatments, ranging from slight humidification to total immersion in aqueous solutions, are used by paper conservators. The sensitivity to water of iron gall inks means that these treatments may cause side effects, including brown halos and iron migration. In this work, these side effects are investigated. The occurrence of transverse migrations to the reverse of the sheet and lateral migrations (halos) was measured on a set of original samples. Most of the visual changes were accompanied by iron migrations, denoting that the side effects also affected the long-term preservation of the manuscript. GORE-TEX ${ }^{\mathbb{B}}$ humidification produced particularly significant migration. This effect was significantly lowered when the humidity decreased. With immersion treatments, the quantity of migration increased with the addition of alcohol to the water, indicating a competition between water-soluble compound extraction in the solvent and their migration in the paper. Paper conservators routinely perform ink solubility testing before undertaking treatment. These tests were reproduced and evaluated with water absorption measurements. They proved to be unreliable, especially when the paper was hydrophilic.

\section{INTRODUCTION}

Iron gall inks were commonly used for writing until the early twentieth century. They consisted of a mixture of vitriol, an iron(II) sulphate-related product, with tannins and gum arabic $[1,2]$. Original recipes available for iron gall ink show considerable variation in both the ingredients and the respective quantities used. The chemistry of iron gall ink is also very complex. Iron gall inks may age very differently depending on their initial composition, on the paper characteristics and on the storage conditions. They are mostly known for their ability to accelerate paper degradation by promoting the browning of the paper and a loss of its mechanical properties. A considerable amount of research has been done in the last 20 years on iron gall ink corrosion and on curative treatments [3-5]. When studying the related bibliography, one may conclude that iron gall ink is a serious threat to our written patrimony. This is probably true for collections that are exposed to tropical climates,

Received January 2009 as humidity and high temperatures are two essential factors for damage to occur: high humidity promotes iron migration in the paper and it also encourages its interaction with the cellulose, and high temperatures accelerate reaction rates. However, the vast majority of archives kept in temperate climates are relatively well preserved and extreme situations where documents deteriorate into dust are exceptional. While some iron gall ink corrosion can be noticed, especially on the thickest part of the ink lines, the text usually remains legible and the sheet remains relatively easy to handle.

This research focuses on a large archival collection of manuscripts from the French royal prison La Bastille now owned by the French National Library. During the French Revolution, this collection was partly destroyed and many of these manuscripts were hidden for a long period in cellars. The National Library now wishes to make the collection available to the public. Only slight iron gall ink corrosion is noticed in this collection, but many of the sheets require conservation treatment. For example, some papers are spoiled with mud and are illegible (Figure 1), some are crumpled and others present large lacunae. 


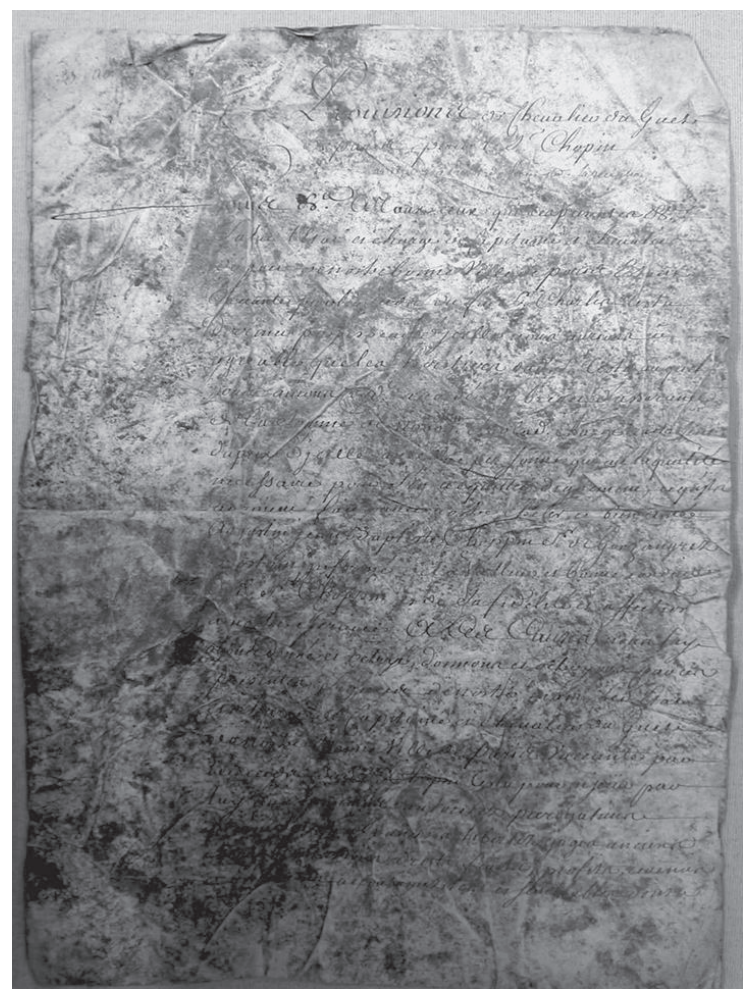

Figure 1 Example of a manuscript from La Bastille covered with mud.

For many reasons, water is the preferred solvent used by paper conservators on paper objects [6, 7]: it reactivates hydrogen bonding between the cellulose chains and it has a positive impact on the paper; it is a powerful solvent for unwanted stains or for paper degradation products; and many physical and chemical treatments such as leaf casting and de-acidification are performed with water-based solutions. Consequently, paper objects may be exposed to water in a number of treatments ranging from humidification to immersion in a wash bath. However, the choice of treatment may be limited by the sensitivity to water of the inks. In order to estimate the risk, paper conservators use ink solubility testing before treatment. These tests are not standardized and paper conservators use a variety of methods and techniques. In addition, a survey organized by the Metal in Paper European Network (EVK4-2002-20010) showed that there was no real consensus in the paper conservation community regarding the water sensitivity of iron gall inks. Moreover, although most paper conservators mentioned performing solubility tests, few considered it as completely reliable, and the question of the reliability of iron gall ink solubility testing remained open to debate.

Paper conservators have different responses when confronted with an iron gall ink that tends to bleed in water. However, these responses are difficult to evaluate rigorously in the working environment. When making a decision, paper conservators are influenced by their personal experience and by some arguments that seem logical. For example, as pure iron gall inks are not alcohol-soluble, mixtures of water and alcohol are often suggested to limit the migration risk. Another approach can be found at the Conservation Center for Art and Historic Artifacts (Philadelphia); there, conservators decided to immerse a collection of 5000 manuscripts in an alcohol bath before applying an aqueous conservation treatment. This alcohol pretreatment was intended to reduce the risk of ink migration [8].

In order to evaluate these different conservation practices more rigorously, it was necessary to investigate in greater detail the side effects caused by the water solubility of iron gall inks. The aim of this research was to compare several aqueous treatments in order to identify the least damaging. These treatments had to be performed on the same set of manuscripts. Therefore working on valuable samples was impossible. Consequently, samples were created by sacrificing some valueless manuscripts. While the ink recipes used for these manuscripts were probably different from those in the collection of La Bastille, this was felt to be of secondary importance. Apart from the detection of iron(II), there is no way to determine the composition of an iron gall ink in a conservation workshop. When deciding upon a treatment, a risk assessment approach should be developed, based on preliminary testing. This approach is effectively identical for all iron gall ink manuscripts whatever the composition of the ink.

Each manuscript selected for this work was cut into several samples, each of them being submitted to a different treatment. As the different samples originated from the same manuscript, it was possible to compare the effects induced by some of the paper conservation practices and to evaluate the relevance of diagnostic tools, such as paper water absorption or ink solubility testing. The evaluation of the migration phenomena was undertaken first using a visual approach followed by elemental measurements. The visual approach aims to identify the formation of undesirable brown halos on the recto and verso of the manuscript. These halos are caused by the migration of brown water-soluble products. These products, whose chemical composition was not included 
in this work, are thought to be cellulose and ink degradation by-products. The elemental measurements aimed to identify the changes in elemental composition and the migration of the elements that are characteristic of the ink. Many techniques are available for the elemental analysis of iron gall inks. For instance, protoninduced X-ray emission (PIXE) analysis is often used because this sensitive method allows the detection of traces of elements [9]. However, since the proton beam penetrates the sheet, the PIXE signal gives an averaged response corresponding to the paper thickness, which is not an advantage when studying surface migrations. Moreover, the heterogeneity of the ink distribution on the paper seriously limits the quantitative analysis of the ink composition $[10,11]$. This problem can be partly resolved by the use of mapping techniques [12], but these are time-consuming and only a small number of beam lines are equipped for this. Considering the large number of samples to analyse, an alternative and more accessible technique was selected: scanning electron microscopy (SEM). Although less sensitive, it analyses the surface of the sample only, which allows the visualization of elemental migrations on the verso side.

The analysis mainly focused on the detection of iron, as this element may drastically accentuate paper degradation: iron(II) and iron(III) ions can behave as a Lewis acid. Moreover, iron is well known for its ability to enhance cellulose oxidation, even if the chemical mechanisms involved are not yet clearly established. The examination of original manuscripts in various states of deterioration showed that the ink topology is a determining factor [13]. On the best-preserved examples the ink remained on the surface of the paper. In contrast, on the most degraded documents the iron had spread well into the paper. The migration of iron into the paper is usually considered to be undesirable for the long-term conservation of a manuscript. However, most original papers do contain some traces of iron, inherent in the paper-making process (water quality, iron tools, etc.), so when studying iron migration, acceptable iron contents should be defined. Quantitative analysis performed on a selection of original papers, dating from the fifteenth to the nineteenth century indicated similar iron contents, ranging from 0.1 to $0.4 \mathrm{mg} \cdot \mathrm{g}^{-1}[14,15]$. As all these papers are well preserved, it implies that these amounts of iron do not represent a great threat for long-term conservation. When iron migration leads to concentrations much higher than these values, it should be considered as potentially harmful.

Copper, which might be present in vitriol as an impurity, also has an even stronger negative impact on cellulose. However, this element was not researched in this work because it is only present in trace amounts, and scanning electron microscopy was not sensitive enough to identify its migration. In contrast, sulphur, originating from vitriol, was monitored. Its ability to migrate out of the ink line is already well known [16]. Attention was also paid to the presence of potassium and calcium, as these elements can be found in the gall nut extracts and in the gum [13]. Their impact on iron gall ink corrosion is not fully understood, but these elements were interesting because they may belong to the initial ink composition.

\section{EXPERIMENTAL}

\section{Description of the samples}

Historic manuscripts deemed to have no value were used as sacrificial samples for this research. These manuscripts were well preserved: some browning of the verso was observed, but no cracks or holes were noticeable. The bathophenanthroline test showed that the ink used on all the manuscripts contained iron [17]. Some of the manuscripts dated from the end of the eighteenth century when mixtures of iron gall inks and black or dark blue synthetic dyes came into use. On these samples the ink remained light to dark brown and no dark discharge was observed on the bathophenanthroline tests. So it is reasonable to suppose that no water-soluble synthetic dyes were present in the inks.

The first experiments involved a small group of 13 manuscripts known as 'set A' on which the GORE$\mathrm{TEX}^{\circledR}$ humidification technique and immersion treatments were performed for different durations. The influence of alcohol/water mixtures of the type being used in conservation studios was tested. As no further sampling was possible on the sample set A, a second set of 53 manuscripts called 'set B' was necessary. These came from an archival bundle originating from the south of France. The written text dates from 1818 to 1896 and the paper is handmade and relatively homogeneous. Its visual appearance is similar from one sheet to another. The average thickness of the sheets is $117 \mu \mathrm{m}$, with a standard deviation of $12 \mu \mathrm{m}$. Several pieces of approximately $2-4 \mathrm{~cm}^{2}$ were sampled on each manuscript, each being dedicated to a specific aqueous treatment. All pieces contained thick and thin lines.

\section{Evaluation of ink solubility}

The solubility of the inks was tested using a $0.1 \mu \mathrm{L}$ drop of distilled water placed on a thick ink line area. It was 
immediately covered by a test paper (Whatman no. 1), a 2 $\times 2 \mathrm{~cm}$ square piece of glass, and a $2 \times 2 \mathrm{~cm}$ square piece of paperboard, $2 \mathrm{~mm}$ thick. Finally a $5 \mathrm{~kg}$ weight was placed on top for 20 seconds. The same procedure was repeated three times on the same ink spot. The complete test takes approximately three minutes per sample. A minimum of three solubility tests were repeated on each manuscript. Depending of the intensity of the colour that appeared on the test paper, the manuscripts were classified in three categories:

1 The category called 'insoluble' defined manuscripts for which absolutely no ink stain was observed on the test paper.

2 The category called 'medium soluble' defined manuscripts for which a light ink stain was observed.

3 The category called 'strongly soluble' defined manuscripts for which a dark ink stain was observed.

\section{Evaluation of paper water absorption}

Although it is not extensively tested by paper conservators, the water absorption of the paper was thought to be a determining parameter for the diagnostic of the ink migration risks. This parameter was quantified by measuring the time necessary for the penetration of a drop of distilled water into the paper. This drop was carefully deposited by a syringe and its gloss was observed under a glancing light. The drop was considered to have penetrated the paper as soon as this gloss became imperceptible.

\section{Aqueous treatments}

Table 1 summarizes the aqueous treatments investigated. These treatments were carried out using distilled water at ambient temperature. Immersions were performed in a large container using approximately 0.5 litre of solution. After all the immersions the excess liquid was removed using a Cobb test blotting paper in contact with the edge of the sample for a few seconds. In order to evaluate the influence of the immersion time, several durations were tested for the sample set A, ranging from 1 to 30 minutes. Saturated calcium carbonate solutions were also tested as they are often presented as being capable of reducing dissolution phenomena. Finally, the impact of the addition of alcohol was evaluated on the sample set B using a 5 minute immersion. This duration was chosen because it was leading to significant, but not systematic migrations, in pure water. Consequently, it should be possible to measure a decrease or an increase
Table 1 List of aqueous treatments performed on the two sample sets

\begin{tabular}{|c|c|c|c|}
\hline Set & Type & Name & Description of the treatment \\
\hline \multirow[t]{8}{*}{ A } & \multirow[t]{6}{*}{ Immersion } & W1 & Immersion for 1 minute in water \\
\hline & & W5 & Immersion for 5 minutes in water \\
\hline & & W15 & Immersion for 15 minutes in water \\
\hline & & W30 & Immersion for 30 minutes in water \\
\hline & & Ca1 & $\begin{array}{l}\text { Immersion for } 1 \text { minute in calcium } \\
\text { carbonate solution }\end{array}$ \\
\hline & & Ca15 & $\begin{array}{l}\text { Immersion for } 15 \text { minutes in calcium } \\
\text { carbonate solution }\end{array}$ \\
\hline & \multirow[t]{2}{*}{ Humidification } & G60 & $\begin{array}{l}\text { Humidification with the GORE-TEX }{ }^{\circledR} \text { kit } \\
\text { for } 60 \text { minutes }\end{array}$ \\
\hline & & $97 \%$ & $\begin{array}{l}4 \text { hours at } 97 \% \mathrm{RH} \text { in the humidification } \\
\text { box }\end{array}$ \\
\hline \multirow[t]{12}{*}{ B } & \multirow[t]{5}{*}{ Immersion } & $100 \%$ & Immersion for 5 minutes in water \\
\hline & & $66 \%$ & $\begin{array}{l}\text { Immersion for } 5 \text { minutes in a mixture } \\
(\mathrm{v} / \mathrm{v}) \text { of } 1 / 3 \text { pure ethanol-2/3 water }\end{array}$ \\
\hline & & $33 \%$ & $\begin{array}{l}\text { Immersion for } 5 \text { minutes in a mixture } \\
(\mathrm{v} / \mathrm{v}) \text { of } 2 / 3 \text { pure ethanol- } 1 / 3 \text { ultra-pure } \\
\text { water }\end{array}$ \\
\hline & & $5 \%$ & $\begin{array}{l}\text { Immersion for } 5 \text { minutes in a mixture of } \\
95 \% \text { ethanol }\end{array}$ \\
\hline & & $0 \%$ & Immersion for 5 minutes in pure ethanol \\
\hline & \multirow[t]{7}{*}{ Humidification } & G30 & $\begin{array}{l}\text { Humidification with the GORE-TEX }{ }^{\circledR} \text { kit } \\
\text { for } 30 \text { minutes }\end{array}$ \\
\hline & & Eth-G30 & $\begin{array}{l}\text { Immersion for } 5 \text { minutes in } 95 \% \\
\text { ethanol, drying for } 2 \text { days, then } \\
\text { humidification with the GORE-TEX }{ }^{\circledR} \text { kit } \\
\text { for } 30 \text { minutes }\end{array}$ \\
\hline & & G60 & $\begin{array}{l}\text { Humidification with the GORE-TEX }{ }^{\circledR} \text { kit } \\
\text { for } 60 \text { minutes }\end{array}$ \\
\hline & & 97\% RH Air & $\begin{array}{l}2 \text { days at } 97 \% \mathrm{RH} \text { in the humidification } \\
\text { box }\end{array}$ \\
\hline & & $97 \% \mathrm{RH}$ & $\begin{array}{l}2 \text { days at } 97 \% \mathrm{RH} \text { in the humidification } \\
\text { box, pressed between two papers }\end{array}$ \\
\hline & & 93\% RH Air & $\begin{array}{l}4 \text { days at } 93 \% \mathrm{RH} \text { in the humidification } \\
\text { box }\end{array}$ \\
\hline & & $93 \% \mathrm{RH}$ & $\begin{array}{l}4 \text { days at } 93 \% \mathrm{RH} \text { in the humidification } \\
\text { box, pressed between two papers }\end{array}$ \\
\hline
\end{tabular}

of migration phenomena with increasing amounts of ethanol.

Humidification treatments were carried out using GORE-TEX $^{\circledR}$ and climatic chambers. The GORE$\mathrm{TEX}^{\circledR}$ humidification (Figure 2) was performed with two $20 \times 20 \mathrm{~cm}$ square GORE-TEX ${ }^{\circledR}$ sheets placed in contact with two $17 \times 17 \mathrm{~cm}$ squares of Cobb test blotting paper, each of them being impregnated with $20 \mathrm{~mL}$ of distilled water. Slight pressure was applied on the top using a $20 \times 20 \mathrm{~cm}$ square piece of glass weighing approximately $0.4 \mathrm{~kg}$. This humidification method was inspired by current practices observed in French conservation studios. It cannot be considered as representative of all GORE-TEX ${ }^{\circledR}$ humidification methods, as other variations, using less water, or less pressure may also be used. 


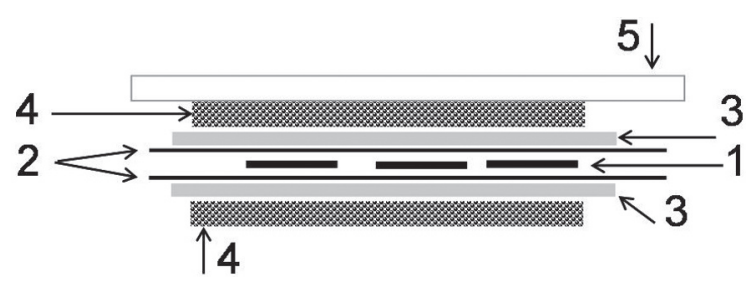

Figure 2 Humidification treatment using GORE-TEX. 1: sample; 2: serigraphic film; 3: GORE-TEX; 4: blotting paper; 5: piece of glass.

Two controlled humidification chambers were set up using saturated salt solutions [18]; one with a relative humidity (RH) of $97 \%$, using potassium sulphate and one with a relative humidity of $93 \%$, using sodium nitrate. Exposure times were largely overestimated compared to the general practice of conservation studios: two days for the exposure at 97\% RH and four days for the exposure at $93 \% \mathrm{RH}$. These values were chosen because they remain lower than, but close to, the maximum time advised to avoid fungi. Two different conditioning systems were tested. In the first, the samples were simply left in the ambient air in the humidification box. In the second, the samples were put under two Whatman papers that were previously conditioned for 3 hours in the humidification box, and gently pressed with a pressure of approximately $1.4 \mathrm{kN} \cdot \mathrm{m}^{-2}$.

After the aqueous treatments all of the samples were dried in an ambient environment. They were placed on a tray between two serigraphic films, and left in an air-conditioned room, at a temperature of $23^{\circ} \mathrm{C}$ and a relative humidity of $50 \%$.

\section{Visual examination and migration factors}

Any visual side effects were evaluated with macro photographs that were taken of each sample before and after treatment. The digital camera was used with a small light booth (Figure 3) equipped with 4300K tungsten halogen lights. The reproducibility of the lighting was checked with a colour test chart. Side effects were classified into three categories: so-called 'transverse migrations', 'lateral migrations', and 'colour and density changes'. The 'transverse migrations' consisted of the migration of coloured compounds through the paper, onto the verso. The 'lateral migrations' dealt more specifically with the migration effects and the formation of halos on the recto side. The "colour and density changes' referred to any change in the aspect of the inks (changes in the hue, fading, etc.).

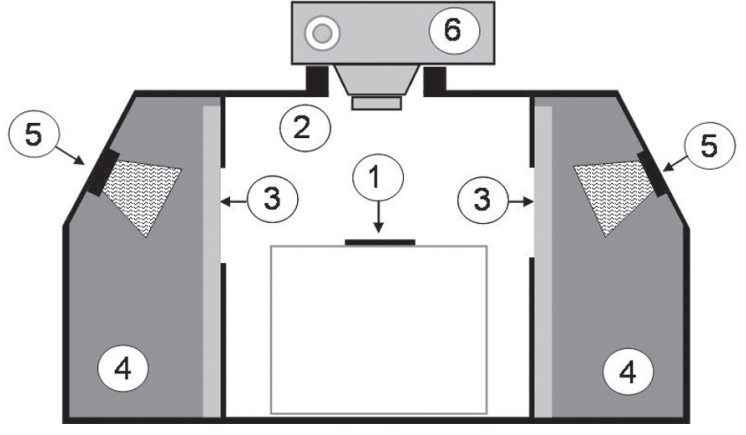

Figure 3 Diagram of the light booth used for this study. The sample (1) is placed at the desired height in a closed box. A diffuse lighting is obtained using white painted walls (2) and ground glass (3). The walls of the two light boxes are painted black (4) in order to absorb the yellow light back-emitted by the four tungsten halogen lights (5) (two on each side). Only direct forward-emitted daylight is allowed to illuminate the sample. Pictures are taken from above (6) through an aperture in the top of the box.

For each category, it was necessary to define two levels of observation (Figure 4). Side effects were considered to be 'obvious' when they were quickly noticeable by the naked eye. They were called 'subtle' when a careful examination of macro pictures before and after treatment was necessary or when they could only be observed by the use of a binocular microscope. In order to quantify and to compare the water sensitivity of the samples, it was necessary to define migration factors: these parameters correspond to the weighted sum of the treatments inducing ink migration. This means that when the migration is obvious the treatment is counted as double. Several migration factors can be determined depending on the type of migration (transverse or lateral) or on the type of treatment to be considered (immersion, humidification, etc.).

\section{Measurement of elemental migration}

Quantitative elemental analysis of the original manuscripts was seriously limited by the heterogeneity of the ink lines. This variability could be attributed to different factors, such as the fibrous paper texture, the size disparity, the writing technique and the heterogeneity of the ink solution, but it could also be attributed to chromatographic effects due to the paper's hydrophilic properties. Scanning electron microscopy allows the mapping of the surface distribution of a given element. At low magnification, it gives a visual and statistical approach of elemental distributions, leading to a qualitative, but sensitive, detection of the ink's elemental 


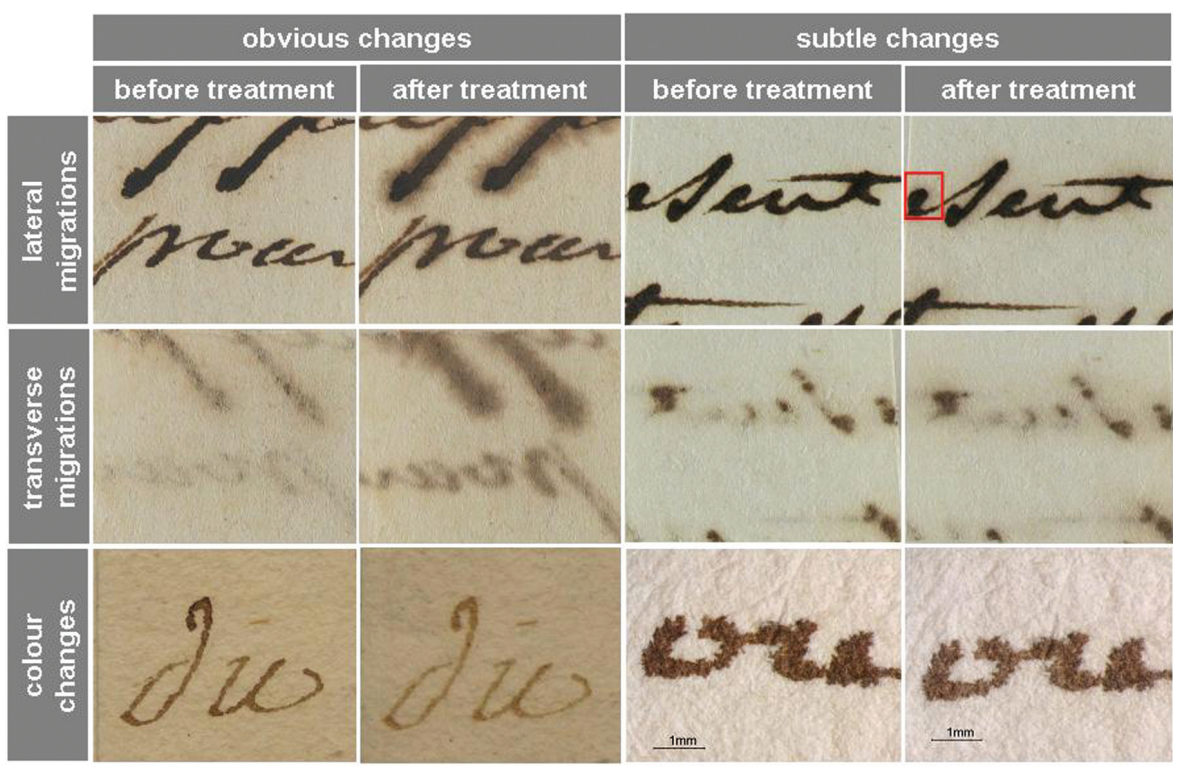

Figure 4 Example of visual side effects observed on originals. The pictures representing the subtle colour changes were taken with a binocular microscope. The other pictures were taken using the light booth depicted on Figure 3. The square defines the area on which the elemental mapping shown in Figure 18 was recorded.

composition. A simple but efficient way to visualize elemental migrations was to record elemental mapping on regions of approximately $3.5 \times 2.3 \mathrm{~mm}$, spanning both virgin and treated areas. For each element, the intensity of the signal was related to the concentration at the sample surface. This concentration decreases if the element is removed from the sample or if it migrates deeper into the paper.

\section{VISUAL EVALUATION OF THE TREATMENTS}

\section{Initial observations on the sample set $A$}

The number of manuscripts presenting side effects was counted (Figure 5). Few obvious side effects were observed when immersion treatments were performed. These observations confirm that the migrations were not easily perceptible in a workshop context. The incidence of migrations tended to decrease with the immersion time, while the risk of colour changes increased. By increasing the immersion time, soluble products were allowed to migrate more easily into the solution, and thus less in the paper. In contrast, the GORE-TEX ${ }^{\circledR}$ treatment was the most harmful. It led to a large number of obvious effects, probably because it introduces an excess of water in the paper, and the soluble compounds can then migrate only in the paper. An exposure to high humidity in a chamber for four hours (treatment '97\%') also proved to induce some ink migration. These occurrences were mostly limited to the verso of the ink line.

For entropic reasons, the use of pure water is usually considered to be more efficient for dissolving soluble compounds than the use of saturated solutions. When testing calcium carbonate solutions, a significant reduction in the risk of ink migration was expected. However, only slight differences were observed when comparing treatment W1 with Ca1, and treatment W15 with Ca15 (see Table 1 and Figure 5), meaning that the entropic effect of pure water does not have a significant impact on migration phenomena.

\section{Influence of the addition of alcohol (sample set B)}

The number of side effects observed on the sample set $\mathrm{B}$ was plotted versus the percentage of water present in the water / alcohol solutions (Figure 6). The percentage of samples giving rise to migrations with pure water 

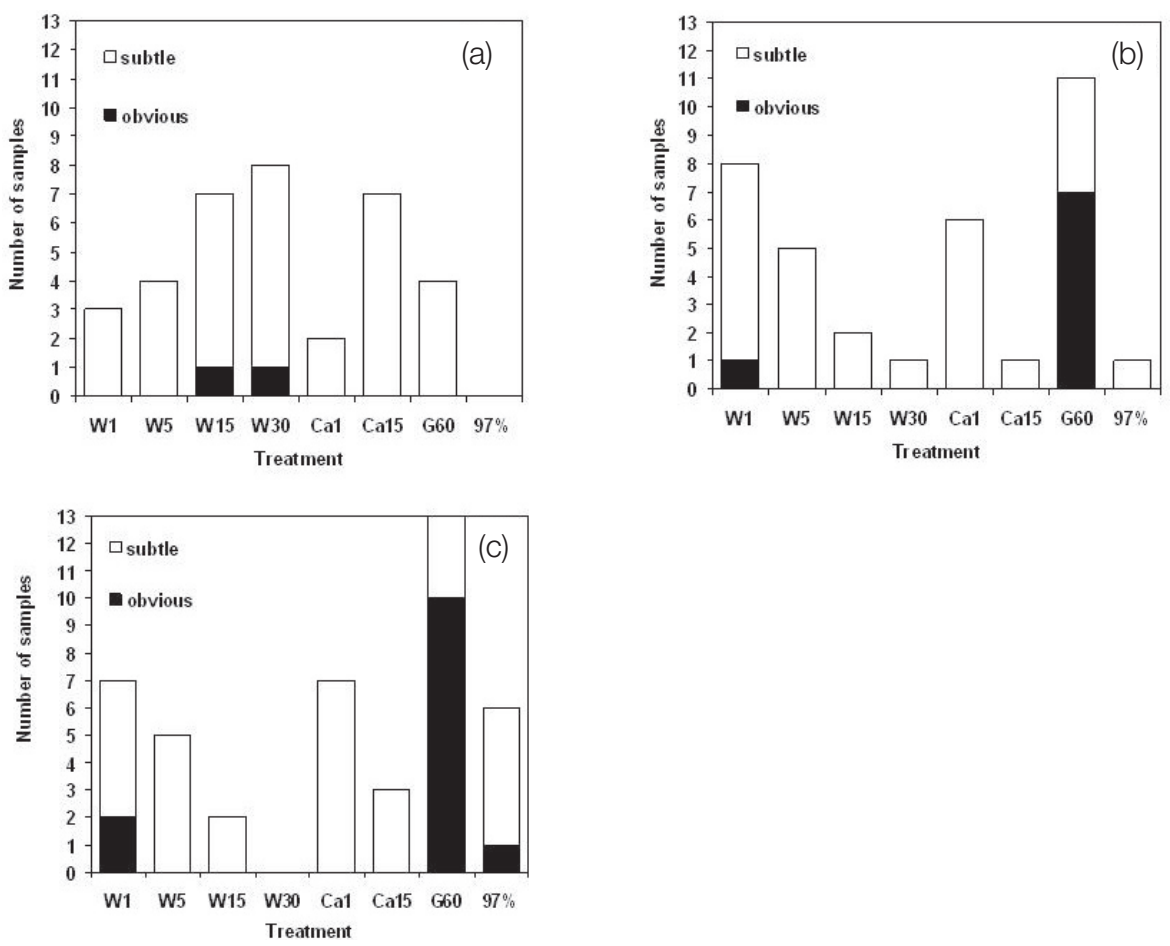

Figure 5 Visual side effects observed on the sample set A: (a) colour changes; (b) lateral migrations; and (c) transverse migrations. All diagrams refer to the number of samples concerned with side effects over a total of 13 samples. The treatments are documented in Table 1. The number of samples concerned with obvious effects is represented in black, and subtle effects in white.

immersions was very consistent with that obtained on the sample set A (Figure 5). The treatment called W15 (Figure 5) was similar to the treatment called 100\% (Figure 6). On both sample sets A and B, these treatments provoked subtle lateral and transverse migrations on approximately half of the samples, suggesting that the sample sets A and B behaved in a similar way.

The number of side effects was increased significantly by the addition of alcohol in water (Figure 6). However, with a level of over $66 \%$ of alcohol (less than $33 \%$ water), the number of side effects suddenly decreased. No effect was observed on pure alcoholic solutions. Two factors may explain the increase of side effects with the addition of alcohol: first, the penetration of water into the paper is favoured by the presence of alcohol; second, the presence of alcohol in the solution limits the extraction of watersoluble compounds. Soluble compounds are also inclined to migrate in the paper.

The possibility of limiting iron gall ink migrations by a pre-immersion in $100 \%$ alcohol was assumed by Choi and Zinsmeister [8]. In order to confirm this assumption, a 30 minute GORE-TEX ${ }^{\circledR}$ treatment was used with and without a pre-immersion for 5 minutes in a 95\% alcoholic solution. The visual examination of these samples (Table 2) showed no obvious advantage in the use of a pretreatment in alcohol, indicating that no fixation of the ink can be expected from this treatment.

\section{Influence of humidity (sample set B)}

Table 3 records the number of migrations resulting from the exposure of the samples to controlled humidity atmospheres. A large number of migrations was observed when the samples were placed in the 'open air'. However, when the samples were gently pressed between two absorbent papers, the migrations were significantly reduced. Two explanations may account for this behaviour: first, the local humidity of the samples may be lower when the sample is pressed between the two absorbent papers, as the three hours conditioning of these papers may not have been sufficient to reach equilibrium; second, the samples conditioned in 'open 

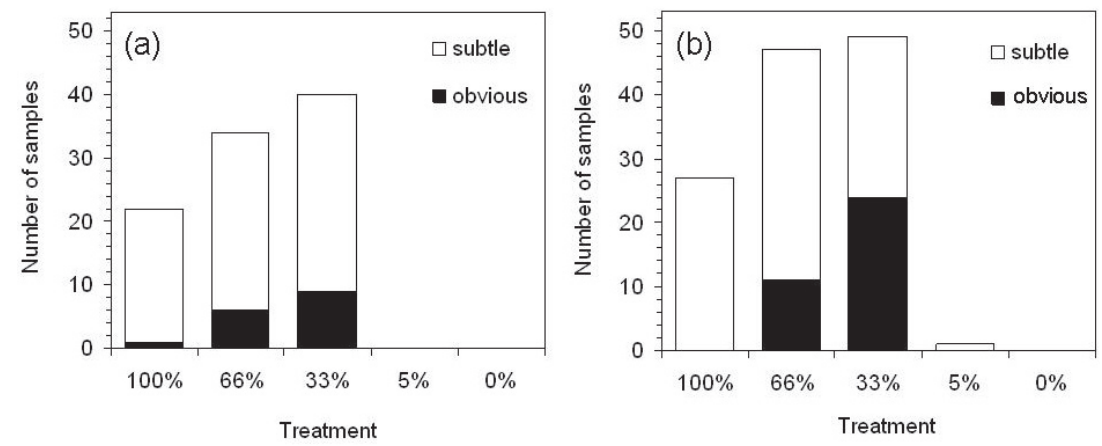

Figure 6 Visual migration observed on the sample set B after the immersion treatments: (a) lateral migrations; and (b) transverse migrations. Both diagrams refer to the number of samples concerned out of a total of 53 samples. The treatments are documented in Table 1. The number of samples showing obvious effects is represented in black (subtle effects in white).

Table 2 Number of samples of set B presenting some ink migration following a GORE-TEX ${ }^{\circledR}$ treatment

\begin{tabular}{lcccc}
\hline Treatment & \multicolumn{2}{c}{ Lateral migration } & \multicolumn{2}{c}{ Transverse migration } \\
\cline { 2 - 5 } & subtle & obvious & subtle & obvious \\
\hline G30 & 19 & 0 & 32 & 10 \\
Eth-G30 & 32 & 2 & 32 & 15 \\
\hline
\end{tabular}

Set $B$ has 53 samples. The treatments are referenced in Table 1

Table 3 Number of samples of set B presenting some ink migration following an exposition to high humidity environments

\begin{tabular}{lcccc}
\hline Treatment & \multicolumn{2}{c}{ Lateral migration } & \multicolumn{2}{c}{ Transverse migration } \\
\cline { 2 - 5 } & subtle & obvious & subtle & obvious \\
\hline $97 \% \mathrm{RH}$ Air & 8 & 0 & 30 & 6 \\
$97 \% \mathrm{RH}$ & 0 & 0 & 4 & 0 \\
$93 \% \mathrm{RH}$ Air & 0 & 0 & 13 & 0 \\
$93 \% \mathrm{RH}$ & 0 & 0 & 0 & 0 \\
\hline
\end{tabular}

Set $B$ has 53 samples. Treatments are referenced in Table 1

air' conditions were exposed to the presence of salt in the vapour, and this may favour water condensation and migration phenomena.

Table 3 also shows that the migration risk was seriously limited when the relative humidity was decreased. However, suggesting 'acceptable' humidity conditions remain difficult, both for practical and theoretical reasons. First, the poor reliability of the hygrometers available in conservation workshops, which currently present uncertainties of $\pm 10 \%$, should be taken into account when determining safe humidification guidelines. Second, the visual assessment only points out large-scale migrations of brown products. For instance, the transverse migrations were observed only when the brown products had crossed the paper thickness, meaning that they reached a distance of approximately $100 \mu \mathrm{m}$. The migration of brown compounds within several tens of micrometres in the thickness of paper was not evaluated with this method. Third, many fundamental questions regarding the migration phenomena in the paper remain open. These phenomena are probably closely related to the occurrence of water condensation. Theoretically, no water condensation happens on a perfectly flat solid surface below 100\% RH. However, paper is not perfectly flat and it has a large distribution of pores causing confined areas in which water condensation may occur below 100\% RH. Indeed, many parameters influence the dew point, such as the temperature, the surface tension of liquid water, and the pore dimension. Kelvin's law was used in order to appreciate the order of magnitude of the pore dimensions susceptible to lower significantly the dew point. It shows that condensation occurs far below $90 \%$ when the pore radius is less than $10 \mathrm{~nm}$. Smallangle neutron-scattering measurements performed on original papers [19] indicates the presence of nano-pores with an average radius of approximately 1.5 to $2 \mathrm{~nm}$. According to Kelvin's law, water condensation in 1.5 $\mathrm{nm}$ pores happens above $50 \% \mathrm{RH}$, and in $2 \mathrm{~nm}$ pores above $60 \%$ RH. These estimations, however, remain purely theoretical, since Kelvin's law has its limits. The modelling of condensation phenomena in nanopores is still an open subject for fundamental research, and theoretical calculations cannot replace physical observations. However, it is reasonable to assume that the migration phenomena occurring below 100\% RH result 
from condensation phenomena in the paper fibre nanopores. These pores may present various distributions: they may be filled with paper size, or be enlarged by paper degradation processes. Because all these parameters may influence the migration risk, it is difficult to suggest 'safe' humidity conditions over 50-60\% RH. The visual assessment performed on this set of samples simply indicates that the migration risk is significant at $95 \%$ $\mathrm{RH}$, but that it is reduced noticeably below 80-90\% RH. It may, however, apply above 60\% RH.

\section{CROSS-CHECKING OF VISUAL ASSESSMENT AND PRELIMINARY TESTING}

\section{Measurement of paper water absorption}

A $1 \mu \mathrm{L}$ drop of water was used on sample set A. As the water absorption of virgin papers differed consistently to that of inked papers, it appeared necessary to measure the water absorption on four separate areas: on virgin paper (recto and verso), and on inked areas (recto and verso). On inked areas, it was noticed that $1 \mu \mathrm{L}$ drops were too large and created wet areas large enough to overlap virgin paper nearby. The resulting measurement of paper absorption included inked and virgin area absorption and was unsatisfactory. To limit this effect, smaller drops of $0.1 \mu \mathrm{L}$ were used. The water absorption performed with $1 \mu \mathrm{L}$ and $0.1 \mu \mathrm{L}$ drops were correlated (Figure 7). This correlation was not linear, but could be interpolated with a second order polynomial function. However, the slope at the origin was very close to 0.1 , meaning that when the paper was hydrophilic, absorption times obtained with $0.1 \mu \mathrm{L}$ drops were ten times smaller than absorption times obtained with $1 \mu \mathrm{L}$ drops. This was no longer the case when the paper was hydrophobic.

Large dispersions were observed in the paper absorption times. These variabilities were attributed to the heterogeneity of the paper. It appeared necessary to consider the average of 10 measurements, each being registered at a different spot. Despite large error bars, absorption measurements registered on both sides of the papers in virgin areas were very similar (Figure 8a): absorption times on recto and verso showed a direct linear correlation. Moreover, most of them corresponded to high absorption times (more than 60 seconds). Even if the size of the paper was not homogeneous, it was not preferentially distributed on one side of the paper. Analogous measurements, performed on inked areas, showed a different behaviour (Figure 8b). For these measurements, most absorption times remained less than 60 seconds, and when high absorption times were

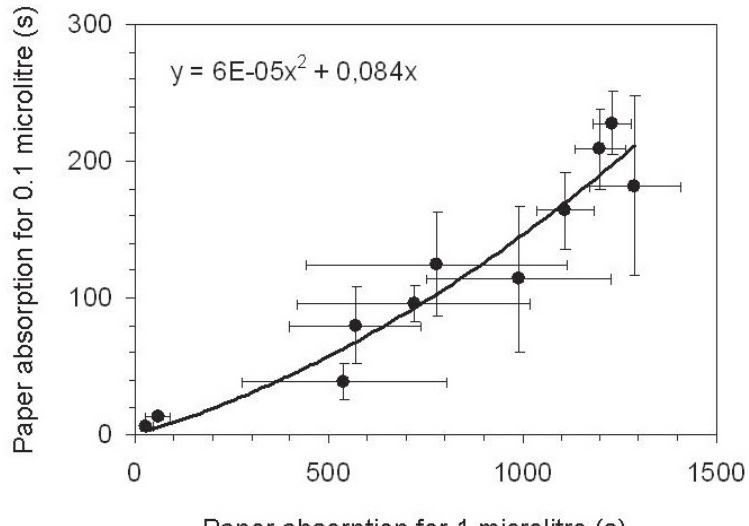

Paper absorption for 1 microlitre (s)

Figure 7 Influence of the water drop volume on paper absorption measurements. Two series of measurements were realized on the same set of samples. The water absorption time is correlated with the initial volume of the drop, but this correlation is not linear.

measured, significant differences between the recto and the verso side of the paper could be noticed.

Three absorption parameters were considered for each sample. The first was an average of the 20 absorption times measured on the recto and verso side of virgin paper. The relative standard deviations of these measurements decreased with the average absorption value (Figure 9). When the paper was strongly sized, it was very hydrophobic, and very low standard deviation values were measured, showing that the size was probably spread more evenly. However, when the paper was hydrophilic, and also less strongly sized, the distribution of this size was probably quite uneven, since high standard deviation values were measured. The second and the third parameters were the average of the 10 absorption times measured respectively on the recto and on the verso of the ink line. In most cases, the paper was more hydrophilic on the ink lines (verso or recto) than on virgin areas (Figure 10). These measurements were coherent with the observations formulated by Reissland [20]. This observation suggests that the paper size might degrade faster on areas where iron gall ink is present.

\section{Paper absorption and transverse migrations}

For the sample set B, the distributions of the transverse and the lateral migration factors, respectively called ' $\mathrm{T}$ ' and 'L', were calculated for the humidification (Figure 11a) and immersion (Figure 11b) treatments as described in Table 1. The treatment 'G60' was not considered for 

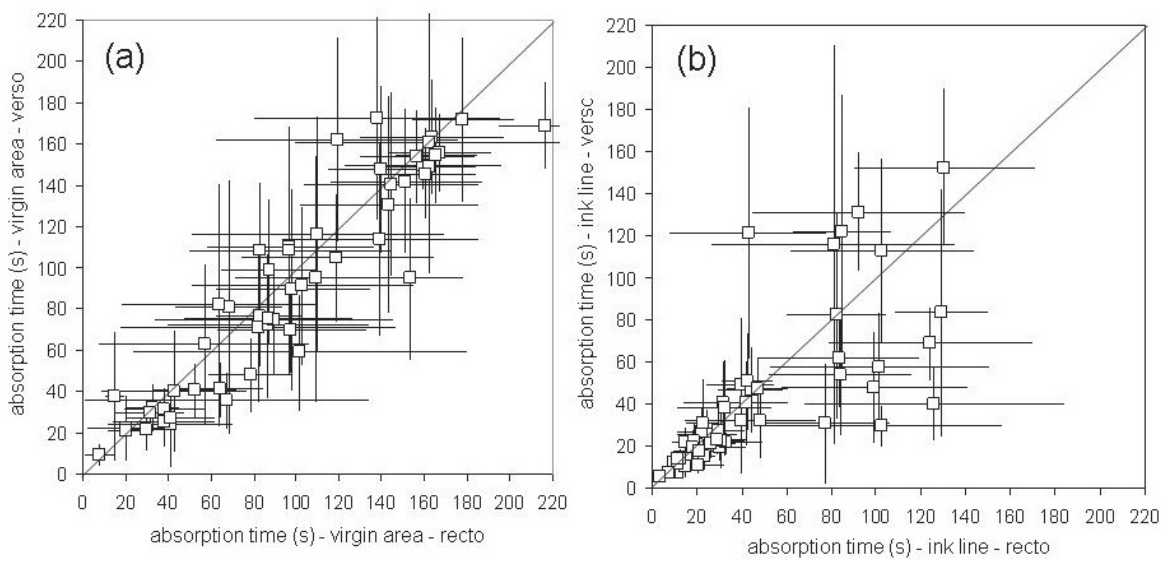

Figure 8 Paper absorption measurements on the different areas of the manuscripts: (a) virgin paper area, recto versus verso; and (b) ink lines, recto versus verso. All values correspond to the average of 10 measurements, performed with $0.1 \mu \mathrm{L}$ drops of water. Error bars correspond to standard deviations.

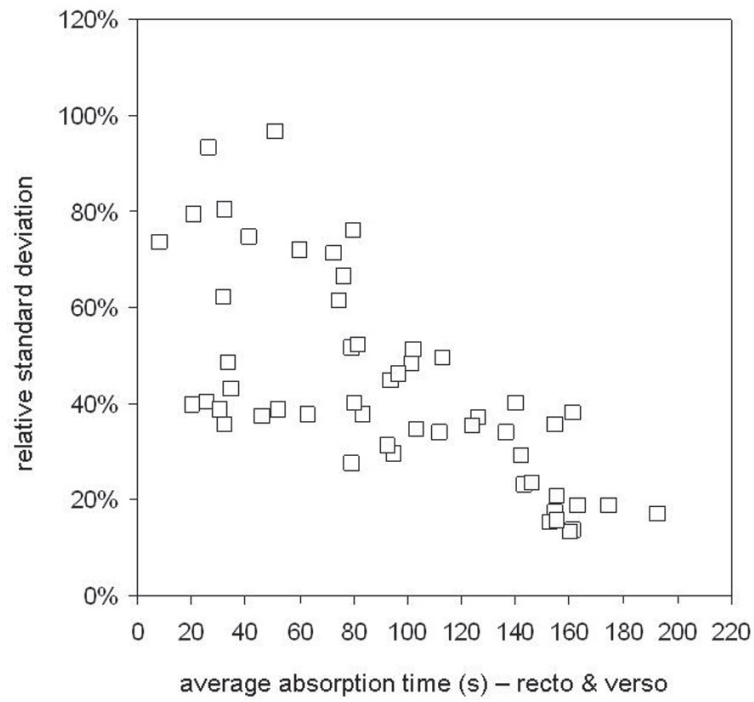

Figure 9 Dispersion of water absorption measurements performed on virgin paper. All values correspond to the average of 20 measurements, performed on the recto and on the verso of the sheet with $0.1 \mu \mathrm{L}$ drops of water. The dispersion of the measurements decreases with the average absorption time.

the calculation of these migration factors. This treatment could obviously not be considered as an immersion treatment but it could also not be considered as a humidification treatment because the samples were wet. Figures $11 \mathrm{a}$ and $11 \mathrm{~b}$ show that, when the samples were

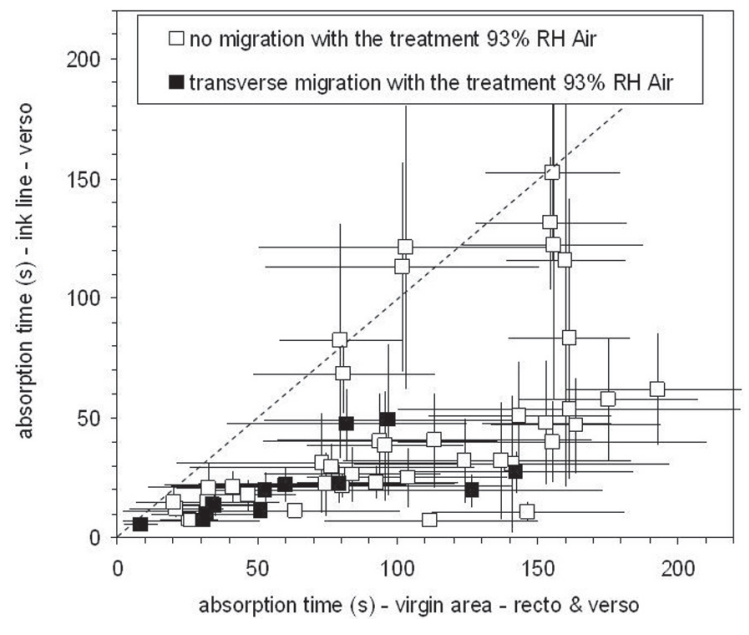

Figure 10 Paper absorption characteristics of the sample set B according to the occurrence of transverse migration after humidification. All measurements are performed with a $0.1 \mu \mathrm{L}$ drop of water. Absorption values on the verso of the ink line correspond to the average of 10 measurements. Absorption values on virgin area correspond to the average of 20 measurements. Error bars correspond to standard deviations.

humidified, transverse migrations were systematically more significant than lateral migrations (Figure 11a). When the samples were immersed, this tendency was less significant, but still perceptible (Figure 11b). The transverse migration risks were also more consistent 

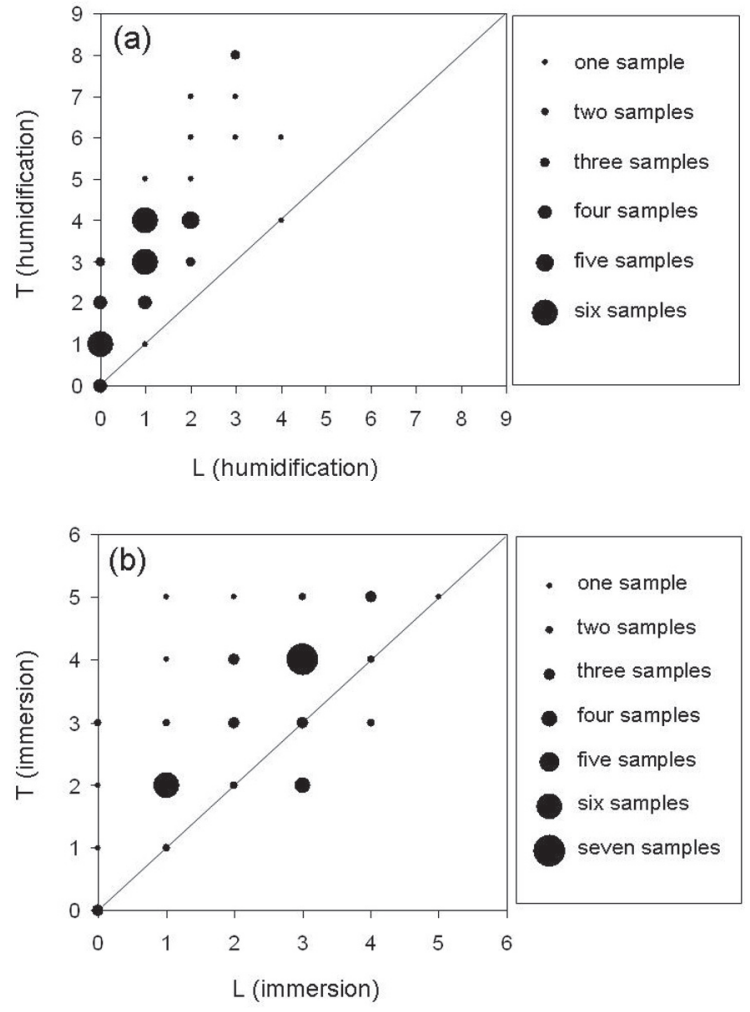

Figure 11 Distribution of lateral and transverse migration factors. The lateral migration factor $L$ and the transverse migration factor $T$ are calculated for all the samples of the set B regarding: (a) all the humidification treatments depicted in Table 1, except 'G60'; and (b) all immersion treatments depicted in Table 1. than the lateral migration risks, probably because the verso of the ink lines was generally more hydrophilic than virgin paper (Figure 10). This effect remains particularly important during humidification such as for the treatment '93\% RH Air'. All the samples presenting some transverse migrations through the treatment ' $93 \%$ RH Air' were also very hydrophilic in the ink line. This observation was consistent with the fact that water condensation happened in the most hydrophilic area of the sample. Indeed, a hydrophilic surface presented a low surface tension, and, according to Kelvin's law, this favours water condensation.

\section{The relevance of preliminary testing}

The ink solubility tests were cross-checked with the migrations resulting from aqueous treatments. This test showed some relevance with the observed effects. For the sample set B, the distribution of lateral and transverse migration factors for all treatments showed that the migrations were statistically more numerous for strongly soluble samples (Figure 12a) than for medium soluble samples (Figure 12b), implying that the intensity of the spot test has some real meaning.

However, this solubility test, when considered alone, is unreliable. Among the sample set B, seven samples were found to be 'insoluble', but on most of these migrations were observed after immersion or GORETEX $^{\circledR}$ treatments (Figure 12c). Only one ink was found to be insoluble and showed no migration. The water absorption parameters give some clues to understand
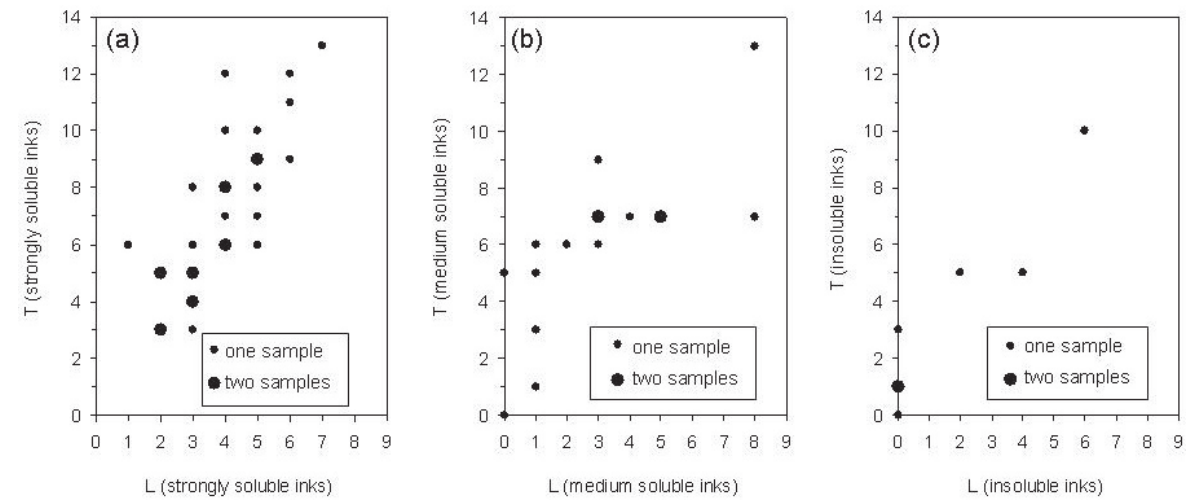

Figure 12 Distribution of lateral and transverse migration factors according to the solubility test evaluation. The sample set B was partitioned in three categories: (a) 'strongly soluble' ink; (b) 'medium soluble' inks; and (c) 'insoluble' inks. For each category, the lateral migration factor $L$ and the transverse migration factor $T$ are calculated for all the treatments depicted in Table 1, except 'G60'. 


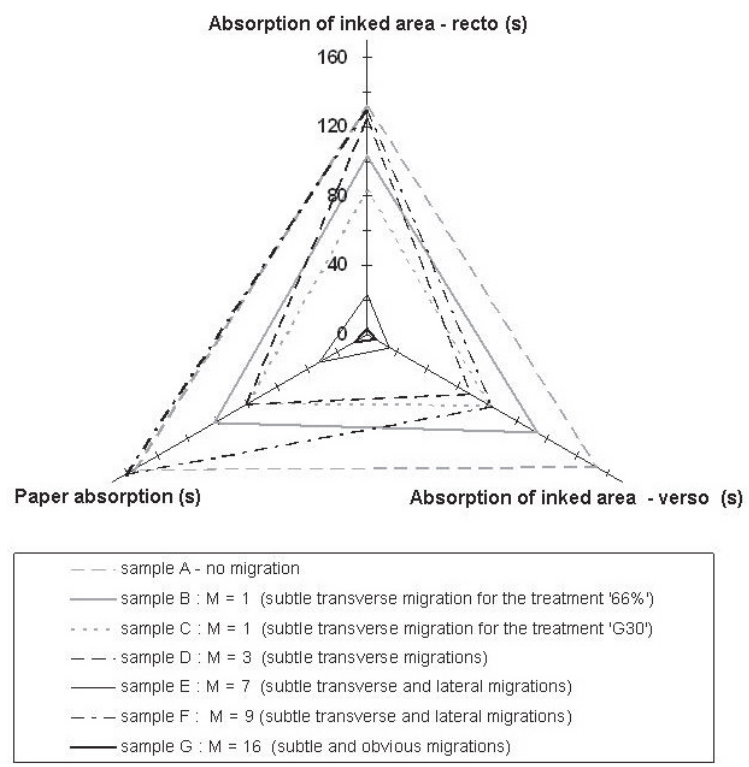

Figure 13 Absorption parameters and migration factors of the set $B$ 'insoluble' samples. For each category, the migration factor $M$ includes both transverse and lateral migrations, and is calculated for all the treatments listed in Table 1, except 'G60'.

this lack of reliability. The absorption parameters of set B 'insoluble' samples (Figure 13) showed that the largest number of migrations corresponded to the most hydrophilic samples (sample E and G) or the most heterogeneous samples, namely those on which the absorption parameters of the virgin paper differed significantly from that of the verso and/or the recto of inked area (sample D and F). On the contrary, when the paper was evenly hydrophobic, few migrations were observed. The lack of reliability of the solubility test can be accounted for by the fact that it is not adapted to hydrophilic papers: if the water drop is quickly absorbed by the paper, and the humidity spread over the thickness of the sheet, the discharge of ink on the testing paper is seriously limited. This gives a misleading result.

The solubility and the absorption parameters were correlated with the resulting migration factors in order to check the relevance of the preliminary testing. Since immersion treatments may favour the elimination of coloured compounds, and also complicate the interpretation of migrations, only the migration factors obtained with the humidification treatments ('G30', 'Eth-G30', '97\% RH', '97\% RH Air', '93\% RH' and ' $93 \%$ RH Air') were considered. The preliminary testing performed on all the samples from set B was crosschecked with the transverse (T) and lateral (L) migration factors (Figures 14a and 14b). The migrations were more limited when the paper absorption on the verso of an

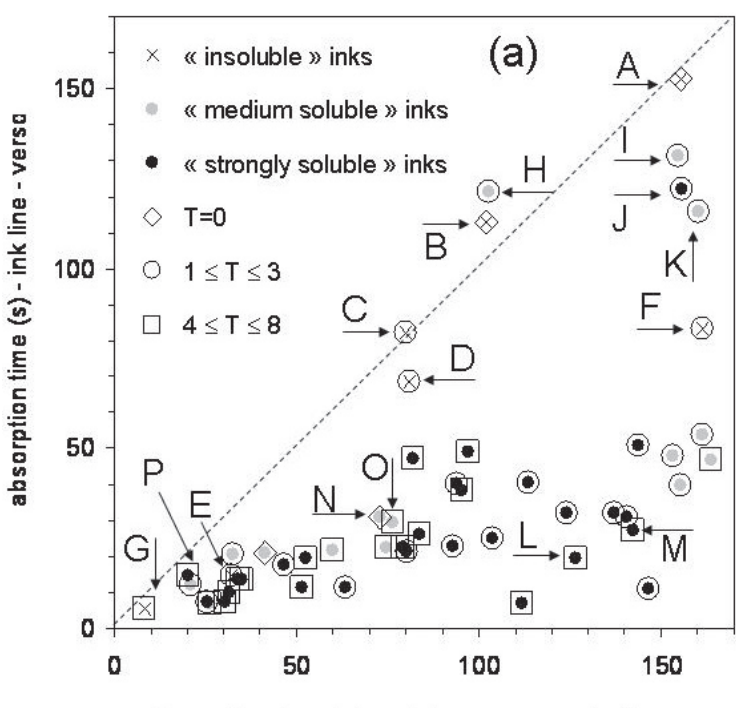

absorption time (s) - virgin paper - recto \& verso

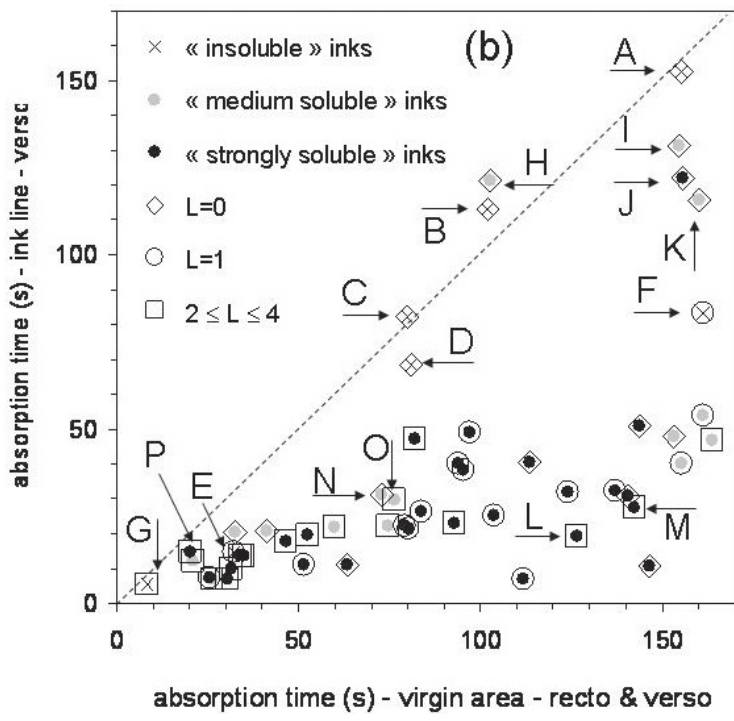

Figure 14 Correlation of preliminary testing and migration factors calculated on the sample set B: (a) lateral migration factor, L; and (b) transverse migration factor, $T$. Absorption values are similar to those represented on Figure 11. $L$ and $T$ are calculated for all the humidification treatments depicted on the Table 1, except 'G60'. 
inked area was close to that of a virgin area. This feature was already pointed out in the case of insoluble inks (sample A to G) and remains valid in the case of soluble inks. For instance, samples $\mathrm{H}, \mathrm{I}, \mathrm{J}$ and $\mathrm{K}$ showed no lateral migration, and only small transverse migrations, although the inks were supposed to be 'medium' or 'strongly' soluble. On the contrary, lateral and transverse migrations were much more numerous when the paper absorption on the verso of an inked area was much lower than that of a virgin area, as in the case of the samples $\mathrm{L}$ and $\mathrm{M}$.

Apart from these general observations, the preliminary tests are not appropriate to assess the ink migrations. Samples presenting similar preliminary test parameters may behave very differently. For instance, the samples $\mathrm{N}$ and $\mathrm{O}$ were both 'medium soluble' and presented the same absorption parameters, yet many lateral and transverse migrations were observed on the sample $\mathrm{O}$, while no migration was observed on the sample $\mathrm{N}$. The procedure used for the preliminary testing remains too simplistic and the migration phenomena too complex to be correlated. However, it is not possible to supplement these tests with other types of preliminary measurements, as the absorption measurements cannot realistically be performed in a conservation studio. Because of the heterogeneity of the ink line and the paper size, many paper absorption measurements need to be performed in order to obtain a realistic average. This time-consuming task may cause small water marks and thus cannot be undertaken on valuable objects.

\section{ELEMENTAL MIGRATIONS}

Three samples (L, M and P) were selected for the measurement of elemental migrations. They belonged to the category 'strongly soluble' and presented rather hydrophilic ink lines. On virgin areas, $\mathrm{L}$ and $\mathrm{M}$ were much more hydrophobic than sample P. The presence of iron, potassium and calcium were identified in the three inks. Sulphur was detected on sample M only. Elemental diffusion were measured for three characteristic treatments: humidification with GORE$\mathrm{TEX}^{\circledR}$ ('G30', 'G60' and 'Eth-G30'); immersion in pure water ('100\%'); and immersion in a mixture of water and alcohol ('33\%'). For each treatment, the behaviour of the three samples was comparable, but each treatment induced different types of migrations (Table 4).

With the GORE-TEX ${ }^{\circledR}$ treatments (Figures 15 and 16), no significant change was perceptible on virgin paper areas. On the contrary, the contents of iron and potassium of the ink line surface decreased significantly, meaning that these two elements impregnated the paper. Additionally, important migrations were observed around the ink line and on the verso of the paper, and these migrations were superimposing visual brown halos. The immersion treatment in a mixture of alcohol and water (treatment '33\%') gave similar pictures to those obtained with GORE-TEX ${ }^{\circledR}$ humidification (Figures 15 and 16), suggesting a similar behaviour: large elemental migrations superimposing the brown halos were measured around the ink lines and through the

Table 4 Migrations observed on the samples L, M and $P$

\begin{tabular}{|c|c|c|c|c|c|c|c|c|c|c|c|c|c|c|c|c|c|c|c|c|}
\hline \multirow{4}{*}{$\frac{\text { Sample }}{\mathrm{L}}$} & \multirow{4}{*}{$\begin{array}{c}\text { thickness } \\
120 \mu \mathrm{m}\end{array}$} & \multicolumn{8}{|c|}{ Absorption measurements (s) } & \multirow[b]{3}{*}{ Treatment } & \multicolumn{10}{|c|}{ Migrations } \\
\hline & & \multirow{2}{*}{\multicolumn{3}{|c|}{$\begin{array}{c}\text { Paper } \\
\text { average }\end{array}$}} & \multicolumn{5}{|c|}{ Ink line } & & \multicolumn{2}{|c|}{ Visual } & \multicolumn{2}{|c|}{ Iron } & \multicolumn{2}{|c|}{ Potassium } & \multicolumn{2}{|c|}{ Calcium } & \multicolumn{2}{|c|}{ Sulphur } \\
\hline & & & & & \multicolumn{3}{|c|}{ recto } & \multicolumn{2}{|c|}{ verso } & & \multirow{2}{*}{$\begin{array}{c}\text { lateral } \\
\text { none }\end{array}$} & \multirow{2}{*}{$\begin{array}{c}\text { transverse } \\
\text { none }\end{array}$} & \multirow{2}{*}{$\frac{\text { recto }}{-}$} & \multirow{2}{*}{$\frac{\text { verso }}{-}$} & \multirow{2}{*}{$\frac{\text { recto }}{-}$} & \multirow{2}{*}{$\begin{array}{c}\text { verso } \\
-\end{array}$} & \multirow{2}{*}{$\frac{\text { recto }}{-}$} & \multirow{2}{*}{$\frac{\text { verso }}{-}$} & \multirow{2}{*}{$\begin{array}{l}\text { recto } \\
\text { not det }\end{array}$} & \multirow{2}{*}{$\begin{array}{l}\text { verso } \\
\text { tected }\end{array}$} \\
\hline & & 127 & \pm & 47 & 30 & \pm & 12 & 20 & \pm 7 & $100 \%$ & & & & & & & & & & \\
\hline & & & & & & & & & & $33 \%$ & subtle & subtle & Y & Y & Y & Y & - & - & & \\
\hline & & & & & & & & & & G60 & obvious & obvious & Y & Y & - & - & - & - & & \\
\hline & & & & & & & & & & Eth-G30 & obvious & subtle & Y & Y & Y & Y & Y & Y & & \\
\hline & & & & & & & & & & G30 & obvious & subtle & Y & Y & Y & Y & - & - & & \\
\hline \multirow[t]{4}{*}{ M } & $110 \mu \mathrm{m}$ & 142 & \pm & 41 & 29 & \pm & 12 & 27 & \pm 8 & $100 \%$ & subtle & subtle & - & - & - & - & - & - & - & - \\
\hline & & & & & & & & & & $33 \%$ & obvious & subtle & Y & Y & Y & - & - & - & - & - \\
\hline & & & & & & & & & & G60 & obvious & obvious & $Y$ & $Y$ & $Y$ & $Y$ & - & - & - & - \\
\hline & & & & & & & & & & G30 & obvious & subtle & $Y$ & Y & Y & $Y$ & - & Y & - & - \\
\hline \multirow[t]{4}{*}{$\mathrm{P}$} & $110 \mu \mathrm{m}$ & 20 & \pm & 8 & 15 & \pm & 3 & 15 & \pm 6 & $100 \%$ & none & subtle & - & - & - & - & - & - & not de & tected \\
\hline & & & & & & & & & & $33 \%$ & subtle & subtle & - & Y & - & - & $\mathrm{Y}$ & Y & & \\
\hline & & & & & & & & & & G60 & obvious & obvious & $Y$ & Y & Y & $Y$ & Y & Y & & \\
\hline & & & & & & & & & & G30 & subtle & subtle & Y & Y & $Y$ & - & $Y$ & - & & \\
\hline
\end{tabular}

' $Y$ ': the element is present in the ink and its migration is indicated; '-': the element is present in the ink, but its migration is not indicated; 'not detected': the presence of the element in the ink is not indicated. 


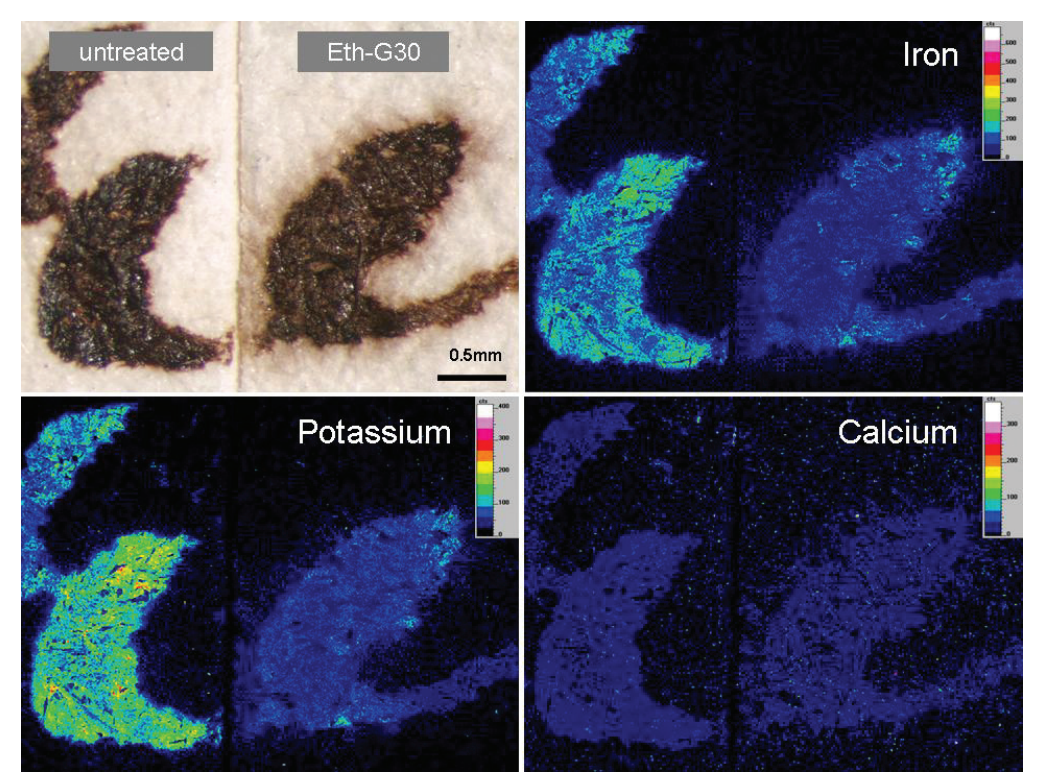

Figure 15 Visual and elemental migrations observed on the recto of the sample L. Right: treated part of the sample; left: untreated part of the sample. The treatment consists of an immersion for 5 minutes in a 95\% ethanol solution, followed, a few days after, by a GORE-TEX ${ }^{\circledR}$ humidification for 30 minutes. The counting rates mentioned on colour scales indicate the statistics of the record (beam energy: $20 \mathrm{eV}$, recording time: 1.5 hour).
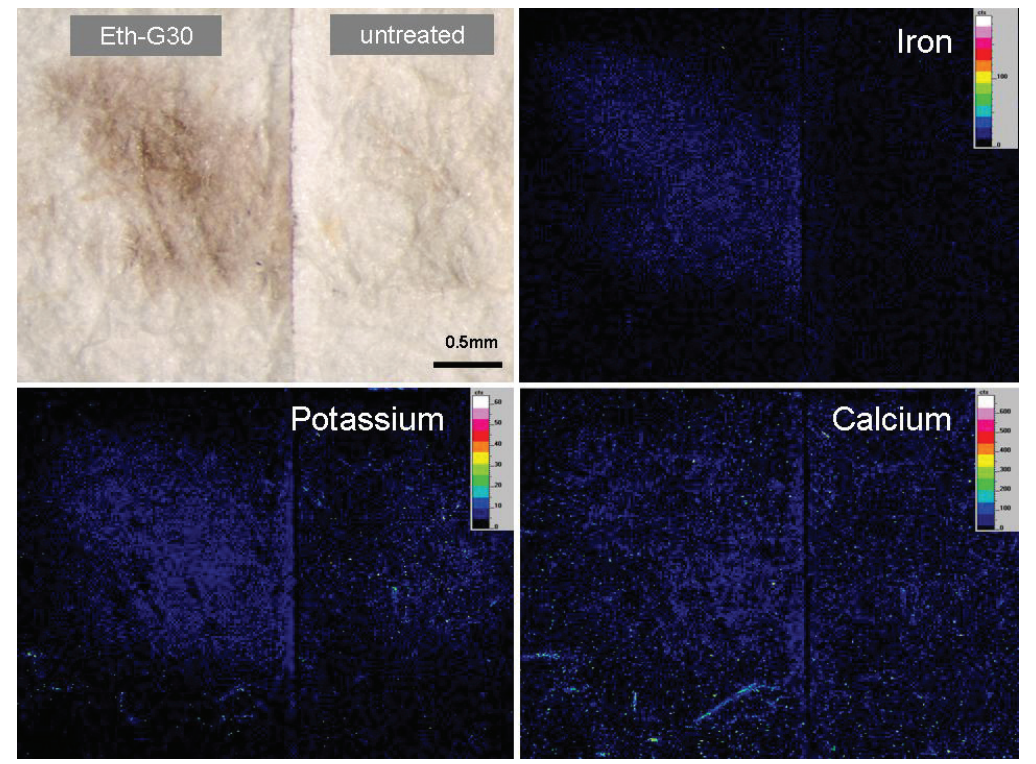

Figure 16 Visual and elemental migrations observed on the verso of the sample L. Left: treated part of the sample; right: untreated part of the sample. The treatment consists of an immersion for 5 minutes in a 95\% ethanol solution, followed a few days after by a GORE-TEX ${ }^{\circledR}$ humidification for 30 minutes. The counting rates mentioned on the colour scales indicate the statistics of the record (beam energy: $20 \mathrm{eV}$, recording time: 1.5 hour). 


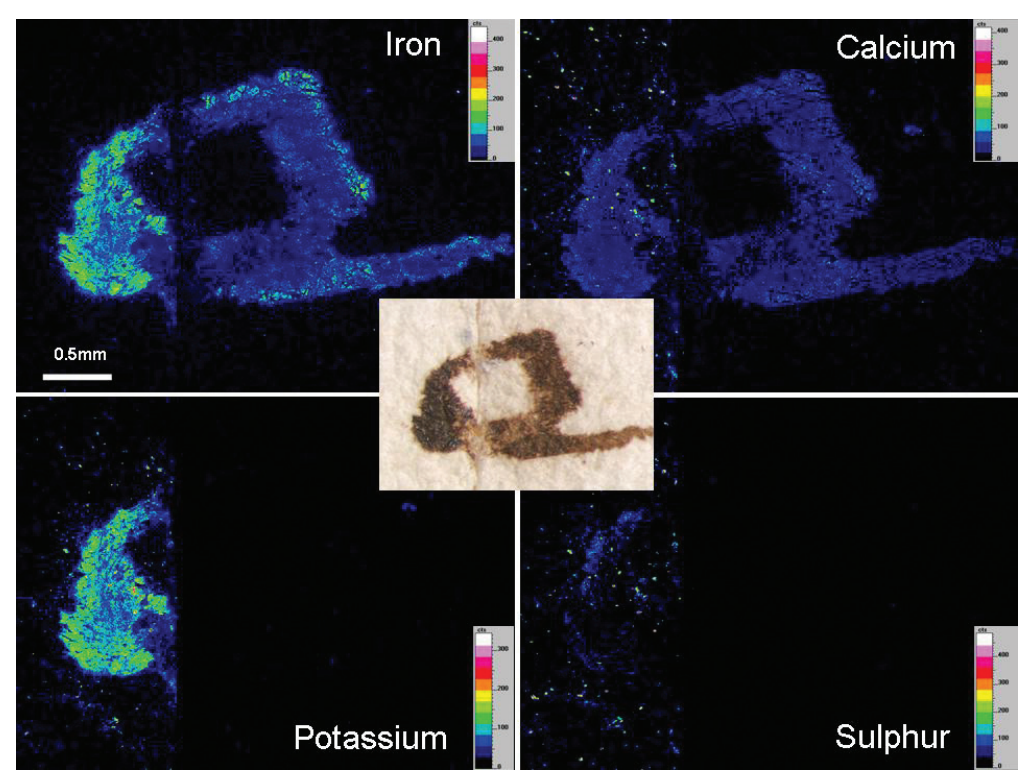

Figure 17 Visual and elemental changes observed on the recto of the sample M. Right: treated part of the sample; left: untreated part of the sample. The treatment consists of an immersion for 5 minutes in pure water. The counting rates mentioned on colour scales indicate the statistics of the record (beam energy: $20 \mathrm{eV}$, recording time: 1.5 hour).

paper, and only slight elemental losses were measured in virgin areas. The immersion treatment in pure water (treatment '100\%') led to very different observations. On the three samples the elemental losses were drastic in virgin areas, but also on ink lines (Figure 17). Most of the calcium, potassium and sulphur disappeared after treatment. On the inked area, potassium and sulphur also totally vanished, but a great part of the iron and calcium remained. Additionally no elemental migration was detected. In order to complete these elemental measurements, mapping was performed on all of the samples that presented some visual halos following an immersion treatment in pure water. All these halos were visually subtle. Initially the experimental parameters outlined in the Appendix were used. No obvious iron migration could be detected using these parameters. The beam energy was then increased to $30 \mathrm{keV}$ in order to analyse a thicker surface layer and to record the map for a period of six hours in order to increase the counting statistics. The measurements were then more sensitive and some iron migration became perceptible (see Figure 18). These measurements, although not quantitative, demonstrate that an immersion in pure water leads to some iron migration around the ink line, but to a much lesser extent than an immersion in a mixture of water and alcohol, or than a humidification treatment with GORE-TEX ${ }^{\circledR}$.

It is important to remember that these observations are purely qualitative. The absence of an element after treatment does not mean that it is totally removed from the sample. Since the penetration of the electron beam into the paper was only several micrometres, scanning electron microscopy remains a surface-sensitive method which is not suited to detecting elemental migration occurring deeper in the paper. Moreover, the sensitivity of this method is limited. The experimental conditions were checked using iron sulphate impregnated papers whose iron content was preliminarily determined by atomic absorption spectrometry. The low detection limit of the experimental procedure was then estimated to be of the order of $2 \mathrm{mg}$ of iron per gram of paper for the maps recorded at $30 \mathrm{keV}$, and $8 \mathrm{mg}$ of iron per gram of paper for the maps recorded at $20 \mathrm{keV}$. These values largely exceed the iron concentration range acceptable for paper conservation (see Introduction). This implies that this methodology is not sufficiently sensitive to detect all the potentially harmful migrations of iron. The use of a quantitative and more sensitive method would probably give more information on the ink dissolution and on its migration in the paper. It would give a better 


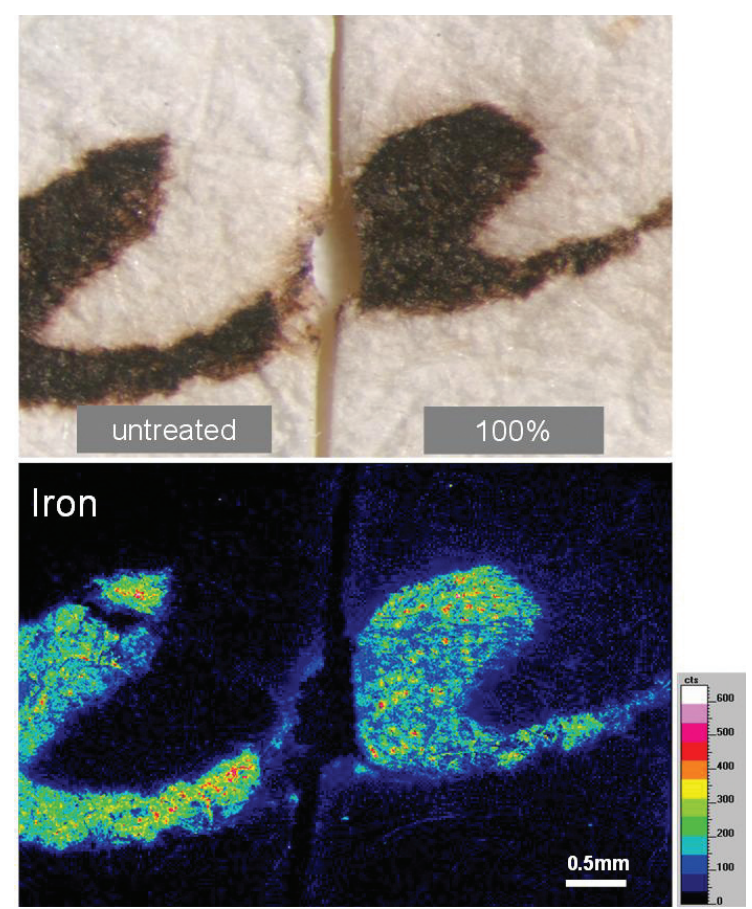

Figure 18 Visual and elemental migrations observed on the recto of the sample O. Right: treated part of the sample; left: untreated part of the sample. A defocused picture of the sample can be found in Figure 4. The treatment consists of an immersion for 5 minutes in pure water. The counting rates mentioned on colour scales indicate the statistics of the record (beam energy: $30 \mathrm{eV}$, recording time: 6 hours).

insight on the competition that certainly happens between these two phenomena. However, the migration of iron detected by this testing should be considered as a potential threat for the manuscript.

Despite not being quantitative, scanning electron microscopy highlights the following behaviours. First, iron migrations were systematically detected on obvious halos and superimpose on the visual halos observed in daylight pictures. This means that the formation of halos during treatments induced damage that was not purely aesthetic. Second, the addition of alcohol in immersion treatments considerably changed migration and dissolution phenomena. It limited the removal of calcium, sulphur and potassium but enhanced elemental migrations into the paper, and specifically iron migrations. By contrast, the use of pure water decreased iron migration around the inscriptions but enhanced dissolution phenomena, leading to drastic changes in the paper composition.

\section{CONCLUSION}

Aqueous treatments are widely used by paper conservators. The water sensitivity of iron gall inks means that these treatments, when performed on Western manuscripts, may cause several kinds of side effects, such as bleeding or formation of halos. Aware of these risks, paper conservators perform ink solubility testing before acting. This work aimed to evaluate these preliminary testing methods and to investigate the side effects induced by different types of treatment intervention.

Most of the visual changes were very subtle and were only detectable with good quality macro photographs taken before and after treatment. As a result, a greater part of the ink migration was imperceptible in the routine work of a conservation workshop. Subtle halos are generally tolerated because they do not significantly alter the legibility of the text. Of more concern is the migration of the iron as part of the brown halo formation, signifying that the iron easily migrates with soluble compounds. As iron enhances cellulose oxidation mechanisms, the side effects not only concern the visual appearance of the document, but also the possibility of long-term physical damage.

Several types of aqueous treatments were tested on a large number of original manuscripts in order to evaluate and compare their risks. Humidification with GORE-TEX ${ }^{\circledR}$, corresponding to $100 \%$ RH, was identified as the most harmful aqueous treatment. The possibility of exposing the manuscripts at a controlled humidity was partially explored. It was found that when the humidity was maintained at a value of less than 80-90\% RH, the migration risk was greatly reduced but not stopped completely. Further investigations are necessary in order to evaluate more precisely which conditions were provoking a migration of iron. As for the treatments by immersion, the addition of ethanol in water limited elemental losses but considerably enhanced the formation of brown halos, and specifically the iron migration around the ink line. These observations demonstrate that there is competition between the extraction of soluble compounds in the solvent and their migration in the paper media. The addition of alcohol favoured the penetration of water in the paper and its access to water-sensitive products. As these products were insensitive to alcohol, their extraction in alcohol/ water solutions was relatively low, compared to that of pure water. Therefore, they were more inclined to migrate into the paper.

A great variety of possible aqueous treatments can be used by conservators and this work cannot be exhaustive. 
It aimed to demonstrate some of the most characteristic behaviours. Conservators who want to apply some specific aqueous treatments are advised to take good quality macro photographs with a reproducible light before and after treatment. This is an efficient method for assessing any side effects of the treatment.

Ink solubility testing and water absorption measurements were performed on each manuscript. The solubility tests, although widely used by paper conservators, appeared unreliable for very hydrophilic manuscripts. The combination of these tests with water absorption measurements was more informative: only a few migrations were observed on the manuscripts on which the ink line was hydrophobic and the solubility test negative. However, the absorption measurements are difficult to carry out in the conservation workshop environment. The unevenness of the paper size means that the water absorption is very different from one area to another. The determination of a quantitative measurement makes it necessary to perform a large number of spot tests which is both time-consuming and harmful to the document, because these may create small water marks. However, a few spot tests performed on the verso of ink lines, although not quantitative, may be useful when the paper is exposed to high humidity conditions, since the more hydrophobic samples were also those on which the fewest migrations were observed.

\section{APPENDIX: ANALYTICAL PROCEDURES}

\section{Identification of the presence of iron with the bathophenanthroline test}

The bathophenanthroline indicator is specific for the detection of iron(II). The Iron Gall Ink Test paper developed at the Instituut Collectie Nederland (ICN, Amsterdam, the Netherlands) consists of paper strips impregnated with bathophenanthroline. The test papers have to be slightly humidified before use and they turn magenta when placed in contact with a material that can release iron(II). Experience shows that this test is very sensitive and capable of identifying diluted iron-based inks.

\section{Preparation of calcium carbonate solutions}

The calcium bicarbonate solutions were prepared by dissolving $1.1 \mathrm{~g}$ of calcium carbonate in a Seltz water production system. The dissolved calcium carbonate was measured using the Titrets tests (Fisher Bioblock Scientific, Illkirch, France, C10309) and was close to 900 $\mathrm{mg} \cdot \mathrm{L}^{-1}$.

\section{Scanning electron microscopy}

Elemental migrations were evaluated by scanning electron microscopy (SEM). An environmental scanning microscope (JEOL, JSM-5410LV), equipped with an X-ray analysing system (OXFORD Link Pentafet), was used to create elemental mappings of the recto and verso of the samples, with a low magnification $(\times 35)$, and with an energy beam of $20 \mathrm{keV}$. Thanks to the low vacuum option, no specific preparation of the samples' surface was necessary. The acquisition was run with the Link Isis software. A satisfactory counting rate statistic was obtained within approximately 1.5 hours of recording.

\section{Estimation of the fungal risk}

The fungal risk was estimated using the Dewpoint calculator software developed by the Image Permanence Institute (Rochester Institute of Technology)

\section{ACKNOWLEDGEMENTS}

This study was founded by the French National Library and by the Fondazione Cassa di Risparmio di Torino. The authors are very grateful to the engineers and the paper conservators of the French National Library for the great interest they took in the project, for their support and advice: Thierry Aubry, Véronique Belon, Madeleine Blouin, Olivier Joly, Alain Lefebvre, Marlène Margez, Thi Phuong Nguyen and Dominique Saligny. The authors are also grateful to Marine Letouzey for performing some of the absorption tests and to Birgit Reissland for fruitful discussions.

\section{SUPPLIERS}

Daylight halogen light: SOLUX, Rochester, USA.

Iron Gall Ink Test Paper: Preservation Equipment Ltd, Norfolk, UK.

Digital camera: Powershot A95, Canon, France.

\section{REFERENCES}

1 Zerdoun, M., Les encres noires au Moyen Âge (jusqu'à 1600), Edition du CNRS, Paris (1983).

2 Stijnman, A.,'Iron gall ink in history: Ingredients and production', in Iron Gall Inks: On Manufacture, Characterisation, Degradation and Stabilisation, ed. J. Kolar and M. Strlic, National and University Library, Ljubljana, Slovenia (2006) 25-67.

3 Banik, G., and Weber, H., Tintenfrassschäden und ihre Bahandlung, Werkhefte der Staatlichen Archivverwaltung Baden-Württemberg, 
Serie A, Landesarchivdirektion; Heft 10, Kohlhammer, Stuttgart (1999).

4 Kolar, J., and Strlic, M., Iron Gall Inks: On Manufacture, Characterisation, Degradation and Stabilisation, National and University Library, Ljublana, Slovenia (2006).

5 Wagner, B., and Bulska, E., 'Towards a new conservation method for ancient manuscripts by inactivation of iron via complexation and extraction', Analytical and Bioanalytical Chemistry 375(8) (2003) 1148-1153.

6 Reissland, B., 'Ink corrosion: Aqueous and non-aqueous treatment of paper objects - State of the art', Restaurator $\mathbf{2 0}$ (1999) 167-180.

7 Reissland, B., and de Groot, S., 'Ink corrosion: Comparison of currently used aqueous treatments for paper objects', in 9th International Congress of IADA, Copenhagen, 15-21 August 1999: Preprints, ed. M.S. Koch (1999) 121-129.

8 Choi, S., and Zinsmeister, M.,'Introducing calcium phytate and calcium bicarbonate in the treatment of historically significant 18th century American iron gall ink manuscripts', in Proceedings of 2nd Iron Gall Ink Meeting, Final European Thematic Meeting for Transitional Metals in Paper, Northumbrian University, Newcastle upon Tyne, 24-27 January 2006, 35-37.

9 del Carmine, P., Giuntini, L., Hooper, W., Lucarelli, F., and Mando, P.A., 'Further results from PIXE analysis of inks in Galileo's note on motion', Nuclear Instruments and Methods in Physics Research: Section B 113 (1996) 354-358.

10 Rouchon, V., Burgaud, C., Nguyen, T.P., Eveno, M., Pichon, L., and Salomon, J., 'Iron gall aqueous treatments: Measurement of elemental changes by proton induced X-ray emission', PapierRestaurierung 9(2) (2008) 18-28.

11 Budnar, M., Vodopivec, J., Mando, P. A., Lucarelli, F., Casu, G., and Signorini, O., 'Distribution of chemical elements of irongall ink writing studied by the PIXE method', Restaurator 22 (2001) 228-241.

12 Remazeilles, C., Rouchon-Quillet, V., Calligaro, T., Dran, J.C., Pichon, L., and Salomon, J. 'PIXE elemental mapping on original manuscripts with an external microbeam: Application to manuscripts damaged by iron gall ink corrosion', Nuclear Instruments and Methods in Physics Research: Section B 181 (2001) 681-687.

13 Rémazeilles, C., Rouchon-Quillet, V., Bernard, J., Calligaro, T., Dran, J.C., Pichon, L., Salomon, J., and Eveno, M., 'Influence of gum arabic on iron gall ink corrosion: Part II. Observation and elemental analysis of originals', Restaurator 26 (2005) 118-133.

14 Stephens, C.H., Barret, T., Whitmore, P., Wade, J.A., Mazurek, J., and Schilling, M., 'Composition and condition of naturally aged papers', Journal of American Institute for Conservation 47 (2008) 201-215.

15 Rémazeilles, C., Etude des processus de dégradation des manuscrits anciens écrits à l'encre ferrogallique, $\mathrm{PhD}$ thesis, University of $\mathrm{La}$ Rochelle, France (2001).

16 Neevel, J.G., 'The behaviour of iron and sulphuric acid during iron-gall ink corrosion', in ICOM Committee for Conservation, 12th Triennial Meeting, Lyon, 29 August-3 September 1999: Preprints, ed. J. Bridgland, James \& James, London (1999) Vol. II, $528-533$.
17 Neevel, J.G., and Reissland, B., 'Bathophenanthroline indicator paper: Development of a new test for iron ions', PapierRestaurierung 6(1) (2005) 28-36.

18 ISO 483: 2005, 'Plastics - Small enclosures for conditioning and testing using aqueous solutions to maintain the humidity at a constant value'.

19 Missori, M., Mondelli, C., De Spirito, M., Castellano, C., Bicchieri, M., Schweins, R., Arcovito, G., Papi, M., and Castellano, A.C., 'Modification of the mesoscopic structure of cellulose in paper degradation', Physical Review Letters 97 (2006) 238001.1-238001.4.

20 Reissland, B., 'Neue Restaurierungsmethoden für Tintenfrass auf Papier mit wässrigen Phytatlösungen - Möglichkeiten und Grenzen', in Tintenfrassschäden und ihre Bahandlung, ed. G. Banik and H.Weber, Kohlhammer, Stuttgart (1999) 113-220.

\section{AUTHORS}

VéRONIQUE ROUCHON has an engineering background (Ecole Polytechnique, Palaiseau, France) and a PhD in material sciences (University of Paris VII, France). She was appointed lecturer at the University of La Rochelle, France, and joined the Centre de Recherches sur la Conservation des Collections (CRCC), France, in 2006 in order to focus her work on paper conservation science. Address: Centre de Recherches sur la Conservation des Collections, Muséum National d'Histoire Naturelle, MNHN-CNRS-MCC, 36 rue Saint Hilaire, 75005 Paris. Email:rouchon@mnhn.fr

Blandine Durocher completed a MA in paper conservation at the Institut National du Patrimoine (INP), France, in 2004. She had a short-term position at the French National Library in 2007 that allowed her to work on the project at the CRCC. More recently, she founded her own private conservation studio. Address: 28 avenue François Mauriac, 93330 Neuilly sur Marne. Email: blandinedurocher-restauration@yahoo.fr

Eleonora Pellizzi graduated in science and technology for cultural heritage at the University of Turin, Italy, in 2008 and is currently undertaking a postgraduate internship at the CRCC (Master dei talenti). Address: as Rouchon.Email:pellizzi@mnhn.fr

Julie Stordiau-Pallot completed a MA in paper conservation at the Institut National du Patrimoine (INP) in 2005. She had a short-term position at the French National Library in 2006 that allowed her to work on the project at the CRCC. She works as a paper conservator. Address: 6 rue de l'Oise, 95300 Pontoise. Email:julie.stordiau@wanadoo.fr 
Résumé - La plupart des manuscrits occidentaux antérieurs au XIXe siècle ont été écrits avec des encres ferrogalliques. Celles-ci sont riches en fer, ce qui favorise la dégradation du papier. Beaucoup de traitements aqueux, allant de la légère humidification à l'immersion totale en solution aqueuse, sont utilisés par les restaurateurs de papier. La sensibilité à l'eau des encres ferrogalliques implique que ces traitements peuvent causer des effets secondaires, notamment des halos bruns et la migration du fer. Ces effets secondaires sont étudiés dans le présent article. On a évalué la migration vers le revers de la feuille ainsi que les migrations latérales (halos) sur un jeu d'échantillons originaux. La plupart des changements visuels étaient accompagnés de migration du fer, indiquant que les effets secondaires ont également un impact sur la conservation à long terme du manuscrit. L'humidification à l'aide de GORE-TEX®, en particulier, produit une migration importante. Cet effet est réduit de façon notable quand l'humidité décroît. Avec les traitements par immersion, le niveau de migration augmente avec l'ajout d'alcool dans l'eau, ce qui dénote une concurrence entre l'extraction par le solvant des composés solubles dans l'eau et leur migration dans le papier. Les restaurateurs de papier réalisent couramment des tests de solubilité de l'encre avant le traitement. Ces tests ont été reproduits et évalués au moyen de mesure d'absorption de l'eau. Ils se sont révélés non fiables, notamment dans le cas de papiers hydrophiles.

Zusammenfassung — Die meisten westlichen Manuskripte vor dem 19. Jahrhundert sind mit Eisengallustinte geschrieben. Diese enthalten Eisen und führen zur Zerstörung des Papiers. In der Papierrestaurierung werden viele wässrige Behandlungen durchgeführt, von einer mäßigen Befeuchtung mit Wasserdampf bis zur vollständigen Wässerung. Die Empfindlichkeit der Tinten gegenüber Wasser hat zur Folge, dass unbeabsichtigte Nebeneffekte wie etwa die Bildung brauner Halos oder die Migration von Eisen auftreten können. In der vorliegen Arbeit werden diese Nebeneffekte untersucht. Das Auftreten von Migrationen durch das Papier hindurch und lateral um den Schriftzug herum (Halos) wurde an einigen originalen Testkörpern gemessen. Die meisten optischen Veränderungen wurden von einer Migration von Eisen begleitet, ein Effekt, der sich auch auf die Erhaltung der Papiere deutlich auswirkt. GORE-TEX ${ }^{\circledR}$ Befeuchtung produzierte erhebliche Migration. Bei geringerer Feuchtigkeit fiel der Effekt geringer aus. Die Migrationsbildung stieg aber bei Zugabe von Alkohol zum Wasser an, was einen Zusammenhang zwischen der Extraktion löslicher Komponenten durch das Wasser und der Migration vermuten lässt. Papierrestauratoren führen normalerweise Löslichkeitstests vor einer Konservierungsmaßnahme durch. Diese Tests wurden nachgestellt und anhand von Tests der Wasseraufnahme evaluiert. Die Tests waren bei hydrophilem Papier nicht verlässlich.

Resumen - La mayor parte de los manuscritos occidentales anteriores al siglo XIX están escritos con tintas ferro-gálicas. Estas son ricas en hierro, el cual acelera la degradación del papel. Muchos tratamientos acuosos, desde la ligera humidificación hasta la total inmersión en soluciones acuosas, son empleados por los conservadores de papel. La sensibilidad al agua de las tintas ferrogálicas implica que estos tratamientos pueden causar efectos derivados, incluyendo la aparición de aureolas pardas y migraciones del hierro. En este trabajo, estos efectos son investigados. La aparición de migraciones transversales, hacia el reverso de la hoja de papel, y aureolas laterales han sido medidos en un grupo de muestras originales. La mayor parte de los cambios visuales estaban acompañados por migraciones del hierro, denotando que estos efectos derivados afectaban a la conservación a largo plazo del manuscrito. La humidificación por GORE-TEX® produjo una migración muy significativa. Este efecto fue significativamente rebajado cuando la humedad disminuía. Con los tratamientos de inmersión la cantidad de migración se incrementaba con la adición de alcohol al agua, indicando esto una competición entre la extracción de componentes solubles en agua y su migración en el papel. Estas pruebas fueron reproducidas y evaluadas con mediciones de absorción de agua; éstas se mostraron impredecibles especialmente cuando el papel era hidrofilico. 